\title{
Spinal cord stimulation in chronic pain: technical advances
}

\author{
Emil Isagulyan ${ }^{1}$, Konstantin Slavin $^{2}$, Nikolay Konovalov ${ }^{3}$, Eugeny Dorochov ${ }^{1}$, Alexey Tomsky ${ }^{1}$, \\ Andrey Dekopov ${ }^{1}$, Elizaveta Makashova ${ }^{4}$, David Isagulyan ${ }^{5}$, and Pavel Genov ${ }^{6}$
}

'Department of Functional Neurosurgery, Federal State Autonomous Institution «N.N. Burdenko National Scientific and Practical Center for Neurosurgery of the Ministry of Healthcare of the Russian Federation», Moscow, Russia

${ }^{2}$ Department of Neurosurgery, University of Illinois at Chicago, Chicago, IL, USA

${ }^{3}$ Department of Spinal Surgery, Federal State Autonomous Institution «N.N. Burdenko National Scientific and Practical Center for Neurosurgery of the Ministry of Healthcare of the Russian Federation", Moscow, Russia

${ }^{4}$ Departament of Neurology, I.M. Sechenov First Moscow State Medical University, Moscow, Russia

${ }^{5}$ Departament of Clinical Science, I.M. Sechenov First Moscow State Medical University, Moscow, Russia

${ }^{6}$ Pain Management Clinic, Moscow City Clinical Hospital \#52, Moscow, Russia

Received December 31, 2019

Revised February 3, 2020

Accepted February 3, 2020

\section{Correspondence}

Pavel Genov

Pain Management Clinic, Moscow City

Clinical Hospital \#52, 3 Pekhotnaya

Ulitsa, 123182 Moscow, Russia

Tel: +7-4991963936

Fax: +7-4991962114

E-mail: genov78@yandex.ru
Chronic severe pain results in a detrimental effect on the patient's quality of life. Such patients have to take a large number of medications, including opioids, often without satisfactory effect, sometimes leading to medication abuse and the pain worsening. Spinal cord stimulation (SCS) is one of the most effective technologies that, unlike other interventional pain treatment methods, achieves long-term results in patients suffering from chronic neuropathic pain. The first described mode of SCS was a conventional tonic stimulation, but now the novel modalities (high-frequency and burst), techniques (dorsal root ganglia stimulations), and technical development (wireless and implantable pulse generator-free systems) of SCS are becoming more popular. The improvement of SCS systems, their miniaturization, and the appearance of new mechanisms for anchoring electrodes results in a significant reduction in the rate of complications and revision surgeries, and the appearance of new waves of stimulation allows not only to avoid the phenomenon of addiction, but also to improve the long-term results of chronic SCS. The purpose of this review is to describe the current condition of SCS and up-to-date technical advances.

Key Words: Chronic Pain; Complex Regional Pain Syndromes; Failed Back Surgery Syndrome; Low Back Pain; Neck Pain; Neuralgia; Pain; Pain Management; Spinal Cord Stimulation.

\section{INTRODUCTION}

The high prevalence of chronic pain syndromes and serious detrimental effect on the patients' quality of life are the reasons why chronic pain remains one of the most important problems of global healthcare. The situation is particularly worse, due to high incidence of chronic pain becoming refractory to conventional treatment. Drug resistance, for example, may be as high as $5 \%$ overall [1]. The prevalence of drug resistance may be much higher for certain groups of pain syndromes. For some, including chronic pelvic pain, it may reach $20 \%-65 \%$ [2], and in patients with chronic neuropathic pain after spinal cord injury, drug resistance occurs to $96 \%$. Such patients have to take large number of medications, including opioids, without satisfactory effect, sometimes leading to medication (a) This is an open-access article distributed under the terms of the Creative Commons Attribution Non-Commercial License (http://creativecommons.org/licenses/by-nc/4.0/), which permits unrestricted non-commercial use, distribution, and reproduction in any medium, provided the original work is properly cited.

(C) The Korean Pain Society, 2020
Author contributions: Emil Isagulyan: Writing/manuscript preparation; Konstantin Slavin: Supervision; Nikolay Konovalov: Resources; Eugeny Dorochov: Writing/manuscript preparation; Alexey Tomsky: Supervision; Andrey Dekopov: Formal analysis; Elizaveta Makashova: Writing/manuscript preparation; David Isagulyan: Investigation; Pavel Genov: Writing/ manuscript preparation. 
abuse and pain worsening. According to a recent study, the average dosage of top gabapentin users for the treatment of neuropathic pain is $9,534 \mathrm{mg} / \mathrm{day}$, which is almost 3 -fold higher than recommended dosage [3]. In addition to this, chronic pain has been shown to be associated with an increased risk of suicidal intent and social isolation.

Since the spinal cord stimulation (SCS) was discovered, it has become one of the most impressive tools in the field of treatment for chronic neuropathic pain. The purpose of this review is describing the current condition of SCS and up-to-date technical advances.

\section{MAIN BODY}

\section{History of SCS}

Fortunately, medically refractory pain may frequently be controlled with interventional approaches, including electrical neurostimulation. Back in March 2017, the medical community commemorated the 50 year anniversary of the first-ever implantation of a SCS device by a neurosurgeon from La Crosse, Wisconsin, named Norman Shealy, who introduced the concept of stimulation of the posterior columns for treatment of severe refractory pain. Since then, SCS has become the most frequently performed surgical procedure for the treatment of chronic pain around the world, replacing all destructive and ablative procedures. SCS was, in essence, a huge step forward in pain management, furthering the understanding of the fundamental mechanisms of nociception. Since that time, the conventional tonic stimulation used by Shealy, and everyone else for the first several decades, has become supplemented by new SCS paradigms, primarily high-frequency (HF), and 'burst' stimulation.

\section{Effect of SCS}

The mechanisms of tonic SCS action are not understood completely. The main mechanism is thought to be related to the 'gate-control' theory of Melzack and Wall $[4,5]$. According to this theory, electrical stimulation of large-fiber neurons blocks transmission of neuropathic pain impulses from primary small-fiber afferents. Other explanations include the effect of SCS on the central mechanisms of pain, in particular, on the phenomenon of central sensitization [6]. Moreover, the studies of SCS in an animal model have shown that stimulation affects the hyperexcitability of the neurons, and this effect may be related to the intracellular glutamate concentration. The effects of SCS on the neurotransmitter systems have been demonstrated in a number of studies $[7,8]$ and are summarized in Table 1.
A different mechanism of SCS action involves its effect on peripheral structures, particularly changes in blood microcirculation in the limbs and at the spinal segmental dermatomes corresponding to levels of electrode implantation [9]. Recent investigations studied the potential role of SCS in neuroprotection, synaptic plasticity, nociceptive signaling, and immune regulation. Studies of cerebrospinal fluid samples in 14 patients with a good effect from SCS showed a statistically significant increase in the cerebrospinal fluid concentrations of certain proteins, including those responsible for neuroprotection (clusterin, gelsolin, mimecan, and amyloid beta-A4 protein), nociceptive signaling (neurosecretory protein VGF), and synaptic plasticity (gelsolin) [10].

\section{Indications and patient selection}

When discussing SCS effectiveness, it is important to mention the patient selection criteria. Incorrect patient selection is likely to be one of the most important reasons for ineffectiveness of stimulation. For example, SCS is often used in patients with nociceptive pain, whereas in the past, the lack of improvement with SCS in these patients has been well documented. Other important criteria that have to be considered in patient selection are the psychological and psychiatric aspects. According to contemporary views, anxiety-depressive disorders can be both a consequence of chronic pain and its immediate cause. In patients with secondary psychological disturbances, SCS results in a reduction of the severity of anxiety-depressive symptoms as demonstrated in many studies. At the same time, SCS is not expected to work well in patients with psychiatric conditions when pain is only a manifestation of the underlying disease (such as somatization, or undiagnosed or undertreated depression). The presence of 'red flags' in psychological tests is associated with an unfavorable prognosis $[11,12]$. The effectiveness of neurostimulation may also be influenced by a so-called 'delay' periodthe time that passes between the trial and permanent SCS implantation. Studies have shown that a longer 'delay' pe-

Table 1. The Influences of the SCS on Neurotransmitter Concentrations

\begin{tabular}{lc}
\hline Neurotransmitter & SCS effect on concentration \\
\hline GABA & Increase \\
Serotonin & Increase \\
Substance P & Increase \\
Noradrenaline & Increase \\
Acetylcholine & Increase \\
Adenosine & Increase \\
Glutamate & Decrease \\
Aspartate & Decrease
\end{tabular}

SCS: spinal cord stimulation, GABA: gamma-aminobutyric acid. 
riod is associated with lower effectiveness of neurostimulation [12].

Current recommendations suggest use of SCS in medically refractory pain. These are criteria of the medical refractoriness of pain syndromes [13]:

1) There should have been a trial of treatment with at least 4 drugs of known effectiveness in neuropathic pain;

2) each of these drugs should have been tried for at least 3 months or until adverse effects prevent adequate dosage or continued treatment;

3) despite this treatment, the intensity of pain should not have been reduced by more than $30 \%$, or should remain at a level of at least 5 on a $0-10$ scale; and/or it should continue to contribute significantly to poor quality of life.

As to the chronicity of pain needed for patients to qualify for SCS, the 3-6-month duration is defined as shortest period to call the condition chronic.

The credibility of neurostimulation has gained significant momentum with completion of several large prospective randomized controlled studies. Overall, SCS has a wide range of indications for the treatment of various chronic pain syndromes that come with different levels of evidence (Table 2) [14-18]. The U.S. Food and Drug Administration has approved SCS for the treatment of pain in the trunk and extremities, including patients with failed back surgery syndrome (FBSS) [19]. According to a systematic review by Taylor et al. [20] involving 78 studies, the use of SCS is associated with significant pain relief (an average $30 \%$ reduction in the visual analogue scale [VAS] compared to baseline). The PROCESS (prospective, randomized, controlled, multicenter trial aims to assess the clinical effectiveness and cost-effectiveness of SCS) study included 100 patients with FBSS, 52 of them making up the SCS group, and 48-the conventional medical treatment group. After 6 months of treatment, half of patients in the SCS group received satisfactory pain relief (50\% and higher), whereas only four patients in the non-SCS group obtained similar results [21].

The evidence of the efficacy of SCS, however, does not reach level A in patients with refractory angina pectoris, with contraindications for cardiac surgery (angioplasty or coronary bypass surgery), and/or with syndrome X. However, many studies point out the potential effectiveness of neurostimulation for these indications. A recent metaanalysis, which included 14 studies and 518 patients, demonstrated the positive effect of SCS on physical activity, a reduction in nitrite consumption, and a lower frequency of heart attacks [22]. This may serve as a rationale for use of SCS as an adjuvant therapy in such patients.

In 2014, members of the Neuromodulation Appropriateness Consensus Committee (NACC) published recommendations on the use of spinal cord and peripheral stimulation in patients with chronic pain and ischemic diseases. Special attention was drawn to the use of SCS in the treatment of critical limb ischemia. The authors pointed out that neurostimulation cannot be considered a true alternative to conventional medical treatment, but significantly improves outcomes when used as an adjuvant treatment [23].

SCS application for the treatment of specific neuropathic pain conditions is supported by multiple studies. Very good results can be achieved with the use of SCS in patients with diabetic painful polyneuropathy (DPN). Slangen et al. [24] demonstrated the great long-term efficacy of spinal neurostimulation in comparison with conventional treatment. SCS significantly reduced pain intensity and improved the quality of life in DPN patients $[25,26]$.

Complex regional pain syndrome (CRPS) has become a great indication for SCS. Published results suggest SCS efficacy in patients with CRPS types I and II [27]. Pain relief of greater than $50 \%$ was demonstrated in $67 \%$ of patients after 33 months of follow-up. According to some authors, it would be advisable to consider the option of SCS implantation after 12-16 weeks of ineffective conservative treatment [28].

Table 2. Results of the Most Significant Latest Investigations of Spinal Cord Stimulation for the Treatment of Different Pain Syndromes

\begin{tabular}{|c|c|c|c|c|}
\hline Study & Year & Pain syndrome & Design & Result \\
\hline Slangen et al. [14] & 2014 & Diabetic painful neuropathy & Prospective, randomized & $\begin{array}{l}36 \text { patients: } 77 \% \text { responders; 59\% with good effect (significant } \\
\text { pain relief/sleep improvement) }\end{array}$ \\
\hline Zipes et al. [15] & 2012 & Refractory angina pectoris & Multi-center & Mean decrease in heart attacks by $1.2 \pm 2.1$ times \\
\hline Özdemir et al. [16] & 2017 & CRPS & Retrospective & $\begin{array}{l}62 \text { patients with refractory CRPS: significant pain relief, im- } \\
\text { provement in sleep and daily activity in all patients }\end{array}$ \\
\hline Kapural et al. [17] & 2010 & Refractory visceral pain & Retrospective & 35 patients, pain relief more than $50 \%$ in 30 patients \\
\hline Kapural et al. [18] & 2011 & $\begin{array}{l}\text { Refractory visceral pain } \\
\text { (chronic pancreatitis) }\end{array}$ & Retrospective & $\begin{array}{l}30 \text { patients, } 50 \% \text { pain relief in } 80 \% \text {, a year after implantation } \\
\text { Absolute pain relief from } 8.0 \pm 1.6 \text { to } 3.6 \pm 2.0 \text { on VAS } \\
\text { Decrease of opioid uptake }\end{array}$ \\
\hline
\end{tabular}

CRPS: complex regional pain syndrome, VAS: visual analogue scale. 
Table 3. Results of the Most Significant Investigations of Conventional SCS Application for the Treatment of Patients with Low Back and Leg Pain

\begin{tabular}{|c|c|c|c|}
\hline Study & Year & Design & Result \\
\hline Kumar et al. [21] & 2005 & Prospective, randomized, controlled & $\begin{array}{l}52 \text { patients implanted with SCS, } 42 \text { responders } \\
\text { Significant pain relief in } 50 \% \text { of patients after } 6 \text { mo of stimulation }\end{array}$ \\
\hline Barolat et al. [29] & 2001 & Prospective multi-center & $\begin{array}{l}\text { Significant pain relief in } 88 \% \text { of patients with leg pain and in } 88 \% \text { of patients with } \\
\text { low back pain after } 12 \text { mo of follow-up }\end{array}$ \\
\hline North et al. [30] & 2005 & Prospective, randomized, controlled & Significant pain relief \\
\hline
\end{tabular}

SCS: spinal cord stimulation.

Table 4. The Most Significant Investigations of HF and 'Burst' SCS in Patients with Different Chronic Pain Syndromes

\begin{tabular}{|c|c|c|c|c|}
\hline Study & Year & Method & Material & Result \\
\hline Al-Kaisy et al. [31] & 2014 & HF SCS & 82 patients with low back and leg pain & $\begin{array}{l}\text { Successful trial in } 72 \text { patients } \\
\text { Low back pain relief from } 8.4 \pm 0.1 \text { to } 3.3 \pm 0.3 \\
\text { Leg pain relief from } 5.4 \pm 0.4 \text { to } 2.3 \pm 0.3 \text { after } \\
24 \text { mo in course of stimulation }\end{array}$ \\
\hline Deer et al. [32] & 2018 & Burst vs. tonic SCS ${ }^{a}$ & Totally 100 patients: 45 tonic, 55 burst & $\begin{array}{l}\text { Subjects withdrawn: } 4 \\
70.8 \% \text { preferred burst stimulation over tonic } \\
\text { stimulation }(P<0.001) \\
\text { After } 1 \text { yr: } 68.2 \% \text { preferred burst SCS, } 23.9 \% \\
\text { tonic SCS, and } 8.0 \% \text { no preference }\end{array}$ \\
\hline Kapural et al. [33] & 2016 & HF SCS ${ }^{b}$ & 101 patients with low back and leg pain & $\begin{array}{l}\text { Mean relief of low back pain } 66.9 \% \pm 31.8 \% \\
\text { leg pain } 65.1 \% \pm 36.0 \%\end{array}$ \\
\hline Thomson et al. [34] & 2018 & HF SCS & PROCO-RCT, total of 34 patients & $\begin{array}{l}\text { Pain relief (NRS) } \geq 30 \% \text { in } 21 \text { patients, }<30 \% \\
\text { in } 10 \text { patients } \\
\text { After randomization, significant efficacy for all } \\
\text { frequencies }\end{array}$ \\
\hline De Andres et al. [35] & 2017 & HF vs. CF SCS & $\begin{array}{l}\text { Randomized blind effect-on-outcome study } \\
55 \text { patients with FBSS: } 26 \text { HF SCS and } 29 \\
\text { CF SCS }\end{array}$ & $\begin{array}{l}\text { No significant difference between groups in } \\
\text { change of pain intensity, painDetect Ques- } \\
\text { tionnaire scores, Short Form-12 scores } \\
\text { (except social function) }\end{array}$ \\
\hline Al-Kaisy et al. [36] & 2017 & HF SCS & $\begin{array}{l}21 \text { patients with low back pain in patients } \\
\text { without preceding spinal surgery }\end{array}$ & $\begin{array}{l}21 \text { patients, positive test stimulation in } 20 \\
\text { patients } \\
73 \% \text { pain relief on VAS after } 12 \text { mo of stimula- } \\
\text { tion } \\
\text { Decrease of opioid uptake by } 64 \%\end{array}$ \\
\hline Kinfe et al. [37] & 2016 & 8 burst and 6 HF SCS & 14 patients with FBSS & $\begin{array}{l}\text { Trial failure } 2 \text { patients (HF SCS) } \\
\text { Pain relief with 'burst' SCS } 1.8 \pm 0.7 \text { on VAS; } \\
\text { HF SCS } 2.2 \pm 1.0\end{array}$ \\
\hline Muhammad et al. [38] & 2017 & $8 \mathrm{HF}$ and 8 burst SCS & $\begin{array}{l}16 \text { patients with FBSS, with predominant } \\
\text { back pain }\end{array}$ & $\begin{array}{l}87.5 \% \text { pain relief in burst stimulation group } \\
\text { and } 54.9 \% \text { in HF SCS group }\end{array}$ \\
\hline Lambru et al. [39] & 2016 & Cervical HF SCS & $\begin{array}{l}4 \text { patients with chronic migraine; } \\
2 \text { patients with chronic SUNA; } \\
1 \text { patient with chronic cluster headache }\end{array}$ & $\begin{array}{l}\text { Pain relief minimum } 50 \% \text { in all the patients } \\
\text { after } 28 \text { mo in course of stimulation } \\
\text { Complete pain regress in one patient with } \\
\text { chronic SUNA }\end{array}$ \\
\hline Arcioni et al. [40] & 2016 & Cervical HF SCS & 17 patients with chronic migraine & $\begin{array}{l}\text { System implantation in } 14 \text { points } \\
\text { Decrease in number of days with headache by } \\
30 \% \text { in } 7 \text { points }\end{array}$ \\
\hline
\end{tabular}

SCS: spinal cord stimulation, HF: high-frequency, PROCO-RCT: pulse rate on clinical outcomes-randomized controlled trial, NRS: numeric rating scale, CF: conventional-frequency, FBSS: failed back surgery syndrome, VAS: visual analogue scale, SUNA: short-lasting unilateral neuralgiform headache attacks with cranial autonomic symptoms.

aSuccess using neuromodulation with burst (SUNBURST) study, 'system of neurostimulation from ‘Nevro' (SENZA) study.

\section{Technical advances of SCS}

The benefit of conventional SCS has been supported by multiple studies (Table 3) $[21,29,30]$, but the lack of a uniform response to the paresthesia-based tonic SCS prompt- ed introduction of new stimulation paradigms: HF SCS and burst stimulation (Table 4, Fig. 1) [31-40].

One of the main advantages of HF SCS is the absence of paresthesia. Based on published studies, the effectiveness of HF SCS is significantly higher than conventional tonic 


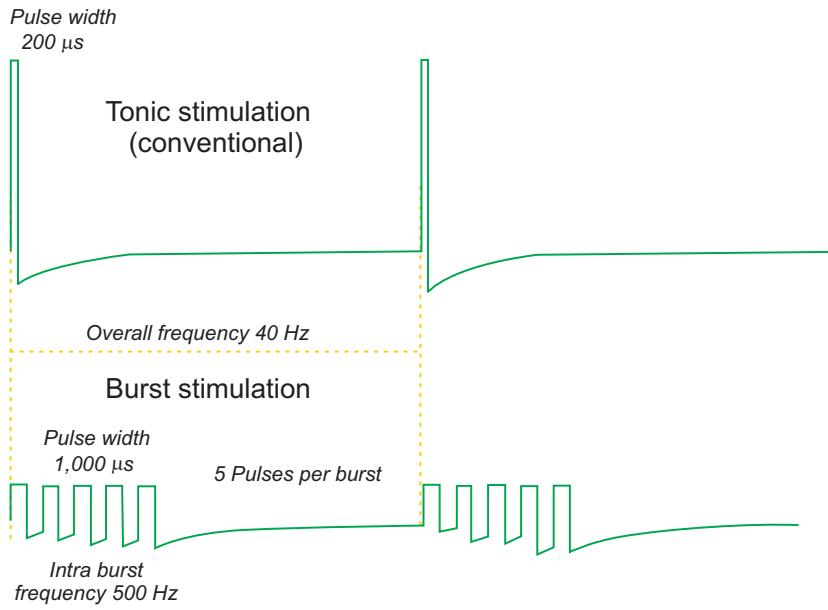

Fig. 1. Stimulation patterns in tonic (conventional) and burst stimulations.

SCS, resulting in claims of 'superiority'. There is no general agreement on the HF SCS mechanism of action, but it is possible that HF SCS works on large axons (with 12-15 mm diameter), leading to the suppression of wide dynamic range neurons without paresthesia [41,42]. Russo et al. [43] performed a retrospective analysis of 256 patients with refractory pain syndromes treated with HF SCS. Mean pain relief after 6 months of follow-up was $50 \%$, while the maximal pain relief ( $81 \%$ and higher) was seen in patients with simultaneous pain in the back and leg.

A multicenter study compared HF SCS with tonic (conventional) SCS and included 101 patients with HF and 97 patients with classic tonic SCS [33]. More than $80 \%$ of patients in both groups had a history of unsuccessful spinal surgery, and almost $90 \%$ of all the patients had received opioids. After 12 months of follow-up, pain relief was significantly higher in the group receiving HF stimulation (65\% in the HF SCS group vs. $45 \%$ in group receiving tonic SCS). After 24 months of follow-up, mean pain relief was $50 \%$, with the average relief of low back pain in the HF SCS group being $66.9 \% \pm 31.8 \%$ vs. $41.1 \% \pm 36.8 \%$ in the tonic SCS group, and leg pain relief was $65.1 \% \pm 36.0 \%$ in the HF stimulation group vs. $46.0 \% \pm 40.4 \%$ in the tonic SCS group. It should be pointed out that in both groups, the number of patients taking opioids significantly decreased, and the patients' quality of life improved.

Most recently published was the multicenter, doubleblind, crossover randomized controlled trial aimed at evaluating the effects of rate on analgesia in HF SCS, which enrolled 34 patients with persistent or recurrent low back pain, with or without equal or lesser leg pain, for at least 90 days prior to the screening. Electronic diaries with numeric rating scale (ED-NRS) were used to evaluate pain intensity during the study. One patient had an unsuccessful stimulation trial, but the remaining subjects were implanted with SCS systems. Ten of them experienced $<30 \%$ pain relief, 1 patient withdrew due to new onset pain, and 20 patients with $\geq 30 \%$ pain relief were randomized and received HF stimulation with frequencies of $1,4,7$, and $10 \mathrm{kHz}$ in random order. All frequencies were found to be equally effective in providing pain relief as measured by ED-NRS $(P \leq 0.002)$. However, mean charge per second differed across frequencies, with $1 \mathrm{kHz}$ SCS requiring $60 \%-70 \%$ less charge than higher frequencies $(P<0.01)[34]$.

Some other studies, however, have reported that HF SCS lacks absolute superiority over conventional tonic stimulation. De Andres et al. [35] completed a prospective, randomized, blind, effect-on-outcome study of conventional versus HF SCS in patients with pain and disability due to FBSS. The authors claimed independence from manufacturer sponsorship. The study enrolled 55 patients with FBSS that were implanted with an SCS system. The study demonstrated that pain relief (measured with the NRS and painDetect questionnaire), in all patients, did not differ based on their treatment by spinal stimulation with conventional or HF SCS, at the one-year follow-up [35].

Burst SCS may act through simultaneous activation of the so-called lateral (somatosensory) and medial (emotional) pain pathways, producing activation of the anterior part of cingulate gyrus and the right dorsolateral prefrontal cortex [44]. Kriek et al. [45] reported that during burst stimulation, decreased hypersensitization of neurons in the posterior horn occurs with simultaneous activation of gamma-aminobutyric acid B-receptors, increasing the inhibitory effects of burst stimulation. De Ridder et al. [46] reported interesting data on the effectiveness of burst stimulation, indicating that burst SCS can be effective in patients with CRPS (pain relief $55 \%$ vs. $31 \%$ with tonic SCS). A double-blind, randomized, placebo-controlled trial, published by Schu et al. [47] compared the efficacy of burst SCS and $500 \mathrm{~Hz}$ HF SCS in patients with FBSS. The study included 20 patients (13 female and 7 male) divided into three groups: placebo (sham) stimulation, $500 \mathrm{~Hz} \mathrm{HF}$ stimulation, and burst stimulation. Mean pain intensity was primarily $5.6 \pm 1.7$ on the VAS. After stimulation, pain intensity on the VAS scale was $7.1 \pm 1.9$ in the $500 \mathrm{~Hz}$ stimulation group, $4.7 \pm 2.5$ in the burst stimulation group, and $8.3 \pm 1.1$ in the placebo group. Mean value in the Oswestry disability index (ODI) before the stimulation was $22.3 \pm 8.0$; after stimulation it was $19.2 \pm 8.0$ in the burst group it was; $24.6 \pm 7.3$ in the $500 \mathrm{~Hz}$ stimulation group, and $29.5 \pm 10.3$ in the placebo group.

A prospective multicenter randomized controlled study success using neuromodulation with burst (SUNBURST) by Deer et al. [32] was aimed to determine the safety and efficacy of a device delivering both traditional tonic 
stimulation and burst stimulation (Fig. 1) to patients with chronic pain of the trunk and/or limbs. The study enrolled a total of 100 subjects with successful results in the tonic trial, that were randomized to receive either burst or tonic stimulation mode for the first 12 weeks, and then the other stimulation mode for the next 12 weeks. The study demonstrated that significantly more subjects $(70.8 \%)$ preferred burst stimulation over tonic stimulation $(P<0.01)$. Preference was sustained through one year: $68.2 \%$ of subjects preferred burst stimulation, $23.9 \%$ preferred tonic, and $8.0 \%$ had no preference. No unanticipated adverse events were reported and the safety profile was similar to other SCS studies.

Another approach that utilizes a new target for neurostimulation, the dorsal root ganglia (DRG), was recently introduced and investigated. DRG stimulation appears to affect neuronal activity through a complex cascade of chemical and electrical responses mediated by its influence on glial cells and microglial cells $[48,49]$. The multicenter prospective randomized controlled trial of DRG stimulation versus SCS analyzed treatment effectiveness in 152 patients with CRPS in the lower extremities and conclusively showed the superiority of DRG stimulation in terms of pain relief, improvement in quality of life, less postural variation, and higher rate of treatment success [50]. According to Eldabe et al. [51], DRG stimulation may also be an option in the treatment of phantom pain: in a small series of 8 patients, significant pain relief (initial mean pain intensity was $83.5 \mathrm{~mm}$ on the VAS, the average pain duration was 14.4 months, mean pain intensity after stimulation was $43.5 \mathrm{~mm}$ on the VAS), and decrease of medication uptake were demonstrated. Weiner et al. [52] reported a pilot study on the efficacy of DRG stimulation using a very different, miniaturized wireless device, in patients with FBSS. Mean pain relief was $59.9 \%$.

In a paradigm-changing concept of closed-loop stimulation, Russo et al. [53] reported the results of a pilot study of the novel SCS system showing remarkably higher success rates. Trial leads were implanted in 51 patients; the final implantation was performed in 36 cases. Three months later, $50 \%$ or more pain relief was found in $92.6 \%$ of patients with low back pain and $91.3 \%$ of patients with leg pain. After 6 months of follow-up, $50 \%$ or more pain relief was seen in $85.7 \%$ of patients with low back pain and $82.6 \%$ of patients with leg pain. At the same time, at least $80 \%$ pain relief was observed in $64.3 \%$ of patients with back pain and in $60.4 \%$ of patients with pain in the leg.

One of the most significant technical advances of recent years is the creation of wireless SCS systems. Systems appeared with an external source of current. With their use, the trial period and the risk of complications associated with the implantable pulse generator and extension cables can be avoided. Contacts are located at the distal end of the electrode and built-in microprocessor (receiver) at the proximal end. The receiver gets electrical impulses from an antenna located outside (at a distance of up to $6 \mathrm{~cm}$ ), which, in turn, receives impulses from an external source. Bolash et al. [54] compared wireless HF $(10 \mathrm{kHz})$ and multi-waveform low-frequency (LF) SCS. Wireless devices reduced FBSS chronic pain substantially with both LF and HF stimulation waveforms over a seven-month period. The patient's VAS scores for back and leg pain decreased significantly: $77 \%$ and $76 \%$ in the cases of HF SCS and $64 \%$ and $64 \%$ in LF SCS patients respectively. In addition, the majority of patients experienced significant improvements in the ODI, European Quality of Life 5 Dimension questionnaire, Patient Global Impression of Change, and sleep duration [54].

Despite the impressive technical developments in the field of SCS made in recent years, the question of the effectiveness of the method in comparison with a placebo continues to be raised. A recent meta-analysis showed limited effectiveness of SCS compared to sham stimulation. The results of this work are disputed, due to methodological issues (small sample sizes, differing SCS modalities, and a possible carryover effect in the crossover design study) [55].

\section{New approaches to reduce the incidence of complications}

Despite the relatively low incidence of complications for conventional SCS (an average incidence of $5 \%$ according to various studies), there are major efforts to reduce them, especially electrode migration. In 2017, NACC published recommendations and guidelines on prevention and management of the main surgical complications of neurostimulation [56-58]. For this, new fixation mechanisms providing a better securing of the electrode position were proposed, and neuromonitoring was suggested to reduce complications related to the electrode insertion. To reduce infectious complications, multiple recommendations have been introduced, with the goal of reducing the prevalence of infections to $1 \%$. Additional improvements in surgical techniques could make spinal stimulation safer for a variety of different patient groups $[11,59]$.

\section{CONCLUSIONS}

Based on recent clinical experience, it may be possible to create an algorithm for choosing the optimal approach to each clinical situation. The algorithm may be based on a combination of the currently available modalities: (a) conventional paresthesia-based stimulation, (b) HF 
stimulation, (c) 'burst' stimulation, and (d) stimulation of DRG. Moreover, the introduction of nanotechnologybased miniaturized stimulators may significantly reduce the general invasiveness of spinal stimulation.

Overall, 50 years after its introduction, SCS has come out of a period of relative stagnation, and is rapidly advancing towards diversification and the creation of the strong evidence base necessary for making science-based decisions in choosing the optimal approach in individual clinical cases.

\section{CONFLICT OF INTEREST}

No potential conflict of interest relevant to this article was reported.

\section{FUNDING}

No funding to declare.

\section{ORCID}

Emil Isagulyan, https://orcid.org/0000-0003-1191-9357

Konstantin Slavin, https://orcid.org/0000-0002-7946-8639

Nikolay Konovalov, https://orcid.org/0000-0003-0824-1848

Eugeny Dorochov, https://orcid.org/0000-0001-5505-408X

Alexey Tomsky, https://orcid.org/0000-0002-2120-0146

Andrey Dekopov, https://orcid.org/0000-0002-3834-5579

Elizaveta Makashova, https://orcid.org/0000-0003-2441-8818

David Isagulyan, https://orcid.org/0000-0002-3001-1590

Pavel Genov, https://orcid.org/0000-0002-5629-9860

\section{REFERENCES}

1. Torrance N, Ferguson JA, Afolabi E, Bennett MI, Serpell MG, Dunn KM, et al. Neuropathic pain in the community: more under-treated than refractory? Pain 2013; 154: 690-9.

2. Shoskes DA, Katz E. Multimodal therapy for chronic prostatitis/chronic pelvic pain syndrome. Curr Urol Rep 2005; 6: 296-9.

3. Peckham AM, Fairman KA, Sclar DA. Prevalence of gabapentin abuse: comparison with agents with known abuse potential in a commercially insured US population. Clin Drug Investig 2017; 37: 763-73.

4. Melzack R, Wall PD. Pain mechanisms: a new theory. Science 1965; 150: 971-9.

5. Vannemreddy P, Slavin KV. Spinal cord stimulation: current applications for treatment of chronic pain. Anesth Essays
Res 2011; 5: 20-7.

6. Krames ES, Foreman R. Spinal cord stimulation modulates visceral nociception and hyperalgesia via the spinothalamic tracts and the postsynaptic dorsal column pathways: a literature review and hypothesis. Neuromodulation 2007; 10: 224-37.

7. Ultenius C, Song Z, Lin P, Meyerson BA, Linderoth B. Spinal GABAergic mechanisms in the effects of spinal cord stimulation in a rodent model of neuropathic pain: is GABA synthesis involved? Neuromodulation 2013; 16: 114-20.

8. Jeon YH. Spinal cord stimulation in pain management: a review. Korean J Pain 2012; 25: 143-50.

9. Cook AW. Letter: percutaneous trial for implantable stimulating devices. J Neurosurg 1976; 44: 650-1.

10. Lind AL, Emami Khoonsari P, Sjödin M, Katila L, Wetterhall $\mathrm{M}$, Gordh T, et al. Spinal cord stimulation alters protein levels in the cerebrospinal fluid of neuropathic pain patients: a proteomic mass spectrometric analysis. Neuromodulation 2016; 19: 549-62.

11. Slavin KV. Spinal stimulation for pain: future applications. Neurotherapeutics 2014; 11: 535-42.

12. Shim JH. Spinal cord stimulation: panacea for incurable diseases? Korean J Anesthesiol 2013; 65: 103-4.

13. Smith BH, Torrance N, Ferguson JA, Bennett MI, Serpell MG, Dunn KM. Towards a definition of refractory neuropathic pain for epidemiological research. An international Delphi survey of experts. BMC Neurol 2012; 12: 29.

14. Slangen R, Schaper NC, Faber CG, Joosten EA, Dirksen CD, van Dongen RT, et al. Spinal cord stimulation and pain relief in painful diabetic peripheral neuropathy: a prospective two-center randomized controlled trial. Diabetes Care 2014; 37: 3016-24.

15. Zipes DP, Svorkdal N, Berman D, Boortz-Marx R, Henry T, Lerman A, et al. Spinal cord stimulation therapy for patients with refractory angina who are not candidates for revascularization. Neuromodulation 2012; 15: 550-8.

16. Özdemir İ, Akbaș M, Yeğin A, Dağıstan G, Erkan DÖ. [Spinal cord stimulation in 62 patients: retrospective evaluation]. Agri 2017; 29: 25-32. Turkish.

17. Kapural L, Nagem H, Tlucek H, Sessler DI. Spinal cord stimulation for chronic visceral abdominal pain. Pain Med 2010; 11: 347-55.

18. Kapural L, Cywinski JB, Sparks DA. Spinal cord stimulation for visceral pain from chronic pancreatitis. Neuromodulation 2011; 14: 423-6.

19. Isagulyan ED, Shabalov VA. Chronic electrical stimulation of the spinal cord in the treatment of failed back surgery syndrome. Hir Pozvonoc 2014; 3: 41-8. Russian.

20. Taylor RS, Van Buyten JP, Buchser E. Spinal cord stimulation for chronic back and leg pain and failed back surgery syndrome: a systematic review and analysis of prognostic factors. Spine (Phila Pa 1976) 2005; 30: 152-60. 
21. Kumar K, North R, Taylor R, Sculpher M, Van den Abeele C, Gehring M, et al. Spinal cord stimulation vs. conventional medical management: a prospective, randomized, controlled, multicenter study of patients with failed back surgery syndrome (PROCESS study). Neuromodulation 2005; 8: 2138.

22. Imran TF, Malapero R, Qavi AH, Hasan Z, de la Torre B, Patel YR, et al. Efficacy of spinal cord stimulation as an adjunct therapy for chronic refractory angina pectoris. Int J Cardiol 2017; 227: 535-42.

23. Deer TR, Mekhail N, Provenzano D, Pope J, Krames E, Leong $\mathrm{M}$, et al. The appropriate use of neurostimulation of the spinal cord and peripheral nervous system for the treatment of chronic pain and ischemic diseases: the Neuromodulation Appropriateness Consensus Committee. Neuromodulation 2014; 17: 515-50.

24. Slangen R, Faber CG, Schaper NC, Joosten EA, van Dongen RT, Kessels AG, et al. A trial-based economic evaluation comparing spinal cord stimulation with best medical treatment in painful diabetic peripheral neuropathy. J Pain 2017; 18: 405-14.

25. Duarte RV, Andronis L, Lenders MW, de Vos CC. Quality of life increases in patients with painful diabetic neuropathy following treatment with spinal cord stimulation. Qual Life Res 2016; 25: 1771-7.

26. van Beek M, Slangen R, Schaper NC, Faber CG, Joosten EA, Dirksen CD, et al. Sustained treatment effect of spinal cord stimulation in painful diabetic peripheral neuropathy: 24-month follow-up of a prospective two-center randomized controlled trial. Diabetes Care 2015; 38: el32-4.

27. Taylor RS, Van Buyten JP, Buchser E. Spinal cord stimulation for complex regional pain syndrome: a systematic review of the clinical and cost-effectiveness literature and assessment of prognostic factors. Eur J Pain 2006; 10: 91-101.

28. Stanton-Hicks M. Complex regional pain syndrome: manifestations and the role of neurostimulation in its management. J Pain Symptom Manage 2006; 31(4 Suppl): S20-4.

29. Barolat G, Oakley JC, Law JD, North RB, Ketcik B, Sharan A. Epidural spinal cord stimulation with a multiple electrode paddle lead is effective in treating intractable low back pain. Neuromodulation 2001; 4: 59-66.

30. North RB, Kidd DH, Farrokhi F, Piantadosi SA. Spinal cord stimulation versus repeated lumbosacral spine surgery for chronic pain: a randomized, controlled trial. Neurosurgery 2005; 56: 98-106.

31. Al-Kaisy A, Van Buyten JP, Smet I, Palmisani S, Pang D, Smith T. Sustained effectiveness of $10 \mathrm{kHz}$ high-frequency spinal cord stimulation for patients with chronic, low back pain: 24-month results of a prospective multicenter study. Pain Med 2014; 15: 347-54.

32. Deer T, Slavin KV, Amirdelfan K, North RB, Burton AW, Yearwood TL, et al. Success Using Neuromodulation with BURST
(SUNBURST) study: results from a prospective, randomized controlled trial using a novel burst waveform. Neuromodulation 2018; 21: 56-66.

33. Kapural L, Yu C, Doust MW, Gliner BE, Vallejo R, Sitzman BT, et al. Comparison of $10-\mathrm{kHz}$ high-frequency and traditional low-frequency spinal cord stimulation for the treatment of chronic back and leg pain: 24-month results from a multicenter, randomized, controlled pivotal trial. Neurosurgery 2016; 79: 667-77.

34. Thomson SJ, Tavakkolizadeh M, Love-Jones S, Patel NK, Gu JW, Bains A, et al. Effects of rate on analgesia in kilohertz frequency spinal cord stimulation: results of the PROCO randomized controlled trial. Neuromodulation 2018; 21: 67-76.

35. De Andres J, Monsalve-Dolz V, Fabregat-Cid G, VillanuevaPerez V, Harutyunyan A, Asensio-Samper JM, et al. Prospective, randomized blind effect-on-outcome study of conventional vs high-frequency spinal cord stimulation in patients with pain and disability due to failed back surgery syndrome. Pain Med 2017; 18: 2401-21.

36. Al-Kaisy A, Palmisani S, Smith TE, Pang D, Lam K, Burgoyne $\mathrm{W}$, et al. $10 \mathrm{kHz}$ high-frequency spinal cord stimulation for chronic axial low back pain in patients with no history of spinal surgery: a preliminary, prospective, open label and proof-of-concept study. Neuromodulation 2017; 20: 63-70.

37. Kinfe TM, Pintea B, Link C, Roeske S, Güresir E, Güresir Á, et al. High frequency $(10 \mathrm{kHz})$ or burst spinal cord stimulation in failed back surgery syndrome patients with predominant back pain: preliminary data from a prospective observational study. Neuromodulation 2016; 19: 268-75.

38. Muhammad S, Roeske S, Chaudhry SR, Kinfe TM. Burst or high-frequency $(10 \mathrm{kHz})$ spinal cord stimulation in failed back surgery syndrome patients with predominant back pain: one year comparative data. Neuromodulation 2017; 20 : 661-7.

39. Lambru G, Trimboli M, Palmisani S, Smith T, Al-Kaisy A. Safety and efficacy of cervical $10 \mathrm{kHz}$ spinal cord stimulation in chronic refractory primary headaches: a retrospective case series. J Headache Pain 2016; 17: 66.

40. Arcioni R, Palmisani S, Mercieri M, Vano V, Tigano S, Smith T, et al. Cervical $10 \mathrm{kHz}$ spinal cord stimulation in the management of chronic, medically refractory migraine: a prospective, open-label, exploratory study. Eur J Pain 2016; 20: 70-8.

41. Arle JE, Mei L, Carlson KW, Shils JL. High-frequency stimulation of dorsal column axons: potential underlying mechanism of paresthesia-free neuropathic pain relief. Neuromodulation 2016; 19: 385-97.

42. Cuellar JM, Alataris K, Walker A, Yeomans DC, Antognini JF. Effect of high-frequency alternating current on spinal afferent nociceptive transmission. Neuromodulation 2013; 16: 318-27.

43. Russo M, Verrills P, Mitchell B, Salmon J, Barnard A, Santarelli D. High frequency spinal cord stimulation at $10 \mathrm{kHz}$ for 
the treatment of chronic pain: 6-month Australian clinical experience. Pain Physician 2016; 19: 267-80.

44. Hou S, Kemp K, Grabois M. A systematic evaluation of burst spinal cord stimulation for chronic back and limb pain. Neuromodulation 2016; 19: 398-405.

45. Kriek N, Groeneweg G, Huygen FJ. Burst spinal cord stimulation in a patient with complex regional pain syndrome: a 2-year follow-up. Pain Pract 2015; 15: E59-64.

46. De Ridder D, Plazier M, Kamerling N, Menovsky T, Vanneste S. Burst spinal cord stimulation for limb and back pain. World Neurosurg 2013; 80: 642-9.

47. Schu S, Slotty PJ, Bara G, von Knop M, Edgar D, Vesper J. A prospective, randomised, double-blind, placebo-controlled study to examine the effectiveness of burst spinal cord stimulation patterns for the treatment of failed back surgery syndrome. Neuromodulation 2014; 17: 443-50.

48. Julius D, Basbaum AI. Molecular mechanisms of nociception. Nature 2001; 413: 203-10.

49. Scholz J, Woolf CJ. The neuropathic pain triad: neurons, immune cells and glia. Nat Neurosci 2007; 10: 1361-8.

50. Deer TR, Levy RM, Kramer J, Poree L, Amirdelfan K, Grigsby E, et al. Dorsal root ganglion stimulation yielded higher treatment success rate for complex regional pain syndrome and causalgia at 3 and 12 months: a randomized comparative trial. Pain 2017; 158: 669-81.

51. Eldabe S, Burger K, Moser H, Klase D, Schu S, Wahlstedt A, et al. Dorsal root ganglion (DRG) stimulation in the treatment of phantom limb pain (PLP). Neuromodulation 2015; 18: 610 6.

52. Weiner RL, Yeung A, Montes Garcia C, Tyler Perryman L, Speck B. Treatment of FBSS low back pain with a novel percutaneous DRG wireless stimulator: pilot and feasibility study. Pain Med 2016; 17: 1911-6.

53. Russo M, Cousins MJ, Brooker C, Taylor N, Boesel T, Sullivan
$\mathrm{R}$, et al. Effective relief of pain and associated symptoms with closed-loop spinal cord stimulation system: preliminary results of the Avalon study. Neuromodulation 2018; 21: 38-47.

54. Bolash R, Creamer M, Rauck R, Vahedifar P, Calodney A, Fox I, et al. Wireless high-frequency spinal cord stimulation $(10 \mathrm{kHz})$ compared with multiwaveform low-frequency spinal cord stimulation in the management of chronic pain in failed back surgery syndrome subjects: preliminary results of a multicenter, prospective randomized controlled study. Pain Med 2019; 20: 1971-9.

55. Duarte RV, Nevitt S, McNicol E, Taylor RS, Buchser E, North $\mathrm{RB}$, et al. Systematic review and meta-analysis of placebo/ sham controlled randomised trials of spinal cord stimulation for neuropathic pain. Pain 2020; 161: 24-35.

56. Deer TR, Lamer TJ, Pope JE, Falowski SM, Provenzano DA, Slavin K, et al. The Neurostimulation Appropriateness Consensus Committee (NACC) safety guidelines for the reduction of severe neurological injury. Neuromodulation 2017; 20: $15-30$.

57. Deer TR, Provenzano DA, Hanes M, Pope JE, Thomson SJ, Russo MA, et al. The Neurostimulation Appropriateness Consensus Committee (NACC) recommendations for infection prevention and management. Neuromodulation 2017; 20: 31-50.

58. Deer TR, Narouze S, Provenzano DA, Pope JE, Falowski SM, Russo MA, et al. The Neurostimulation Appropriateness Consensus Committee (NACC): recommendations on bleeding and coagulation management in neurostimulation devices. Neuromodulation 2017; 20: 51-62.

59. Roth SG, Lange S, Haller J, De La Cruz P, Kumar V, Wilock $\mathrm{M}$, et al. A prospective study of the intra- and postoperative efficacy of intraoperative neuromonitoring in spinal cord stimulation. Stereotact Funct Neurosurg 2015; 93: 348-54. 